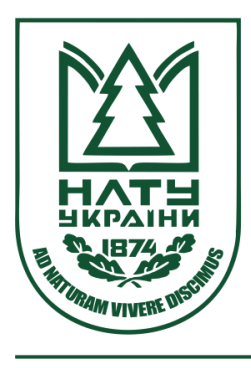

Науковий вісник НлтУ України Scientific Bulletin of UNFU

https://nv.nltu.edu.ua

https://doi.org/10.36930/40290805

$@ \bowtie$ Correspondence author

Article received 18.09.2019 p.

Article accepted 31.10.2019 p.

O. L. Kratiuk

удк 630*521.1:631.1

deneshi_ks@ukr.net

О. Л. Кратюк

Житомирський національний агроекологічний університет, м. Житомир, Украӥна

\title{
ОСОБЛИВОСТІ ВПЛИВУ НАПІВВІЛЬНОГО УТРИМАННЯ МИСЛИВСЬКИХ ТВАРИН НА ДІЕЛЕКТРИЧНІ ПОКАЗНИКИ СОСНИ ЗВИЧАЙНОЇ
}

\begin{abstract}
Досліджено сезонні зміни діелектричних показників сосни звичайної (Pinus sylvestris L.) у вольєрі ДП "Баранівське ЛМГ". Встановлено особливості впливу напіввільного утримання мисливських тварин на інтенсивність проходження процесів життєдіяльності у сосни звичайної. З'ясовано, що незалежно від умов зростання та впливу напіввільного утримання мисливських тварин, діелектричні показники мають чітко виражену динаміку та характеризують сезонні зміни інтенсивності процесів життєдіяльності. Загальну тенденцію простежено у поступовому зниженні величини імпедансу і зростанні поляризаційної ємності під час переходу дерев від стану спокою до вегетації. Так, зокрема, величина поляризаційної ємності у лютому на пробних площах коливалася у межах $4,32^{ \pm 0,24}-5,68^{ \pm 0,17} \mathrm{nF}$, а у червні зросла до $10,08^{ \pm 0,41}-12,15^{ \pm 0,68} \mathrm{nF}$, натомість імпеданс знизився від $33,93^{ \pm 1,65}-44,40^{ \pm 3,79}$ кОм до $17,85^{ \pm 1,16}-21,83^{ \pm 1,35}$ кОм. Подібну закономірність простежено і на контрольних ділянках. Необхідно також відзначити високу індивідуальну мінливість окремих модельних дерев за величиною діелектричних показників (поляризаційна ємність - 13,3-26,7 \%; імпеданс - 16,8-38,2 \%), хоча загалом варіювання $\epsilon$ середнім. Різниця у показниках поляризаційної ємності та імпедансу дослідних і контрольних насаджень сосни звичайної свідчить про негативний вплив напіввільного утримання мисливських тварин на життєдіяльність дерев.
\end{abstract}

Ключові слова: поляризаційна ємність; імпеданс; Pinus sylvestris L.; вольєр.

Вступ. Чільне місце у здійсненні лісівничо-екологічних та селекційно-генетичних досліджень займає вивчення електрофізіологічних параметрів, зокрема імпедансу та поляризаційної ємності - як індикаторів стану деревних рослин (Krynytskyi, 2001). Основи використання електрофізіологічних показників для визначення життєздатності деревних рослин в Україні заклав Г. Т. Криницький (Krynytskyi, 1990).

Нині застосування електрофізіологічних параметрів досить широке. Їх використовують для визначення інтенсивності проходження процесів життєдіяльності деревних порід (Krynytskyi \& Skolskyi, 2015). Діелектричні показники об'єктивно характеризують взаємодії деревних видів у процесі формування деревостанів, а їхні закономірні зміни - різні аспекти функціонування деревних рослин (Karpyn \& Zaika, 2017; Kerimov \& Zaika, 2018). Вони можуть бути індикаторами стану підросту деревних порід на вітровальних ділянках (Lavnyy \& Krynytskyi, 2011), стадій дигресії лісових біоценозів (Derekh, 2014) та реакції дерев на дію несприятливих чинників навколишнього середовища (Zaika, 2004; Krynytskyi \& Zaika, 2004; Krynytskyi \& Halushka, 2005), ступеня пошкодження ентомошкідниками (Melampsora pinitorqua (Br.) Rostr) (Rybak, 2012) та ураження патогенними організмами (Armillariella mellea (Fr. ex Vahl.) Karst., Lophodermium pinastri (Schrad.) Chévall) (Derevjanchuk \& Zaika, 2011; Rybak \& Zaika, 2013), і це не повний перелік сфер застосування. Ми вбачаємо викорис- тання електрофізіологічних показників як перспективний метод індикації стадій впливу мисливської фауни на лісові насадження, особливо у вольєрах. Нині під час планування напіввільного утримання мисливських тварин не існує чітких рекомендацій стосовно відповідності характеристик вольєра (площа, видовий і чисельний склад тварин тощо) та лісівничо-таксаційними показниками лісових насаджень у ньому. Розробці таких нормативних документів значно, на нашу думку, і посприяло б застосування електрофізіологічних показників.

Мета роботи - встановити вплив напіввільного утримання мисливських тварин на інтенсивність проходження процесів життєдіяльності у сосни звичайної (Pinus sylvestris L.).

Матеріали та методи дослідження. Об'єктами досліджень обрали чисті деревостани сосни звичайної, що зростають у межах вольєра на території Явненського лісництва ДП "Баранівське ЛМГ" Житомирського обласного управління лісового і мисливського господарства. Контролем були насадження з аналогічними лісівничо-таксаційними показниками поза межами вольєра (табл. 1). Закладено 8 пробних площ (ПП), а саме: чотири (ПП №1-ПП №4) на території вольєра та чотири контрольних (ПП №1к-ПП №4к). У межах кожної ПП відбирали по 20 модельних екземплярів із числа панівних у фітоценозі дерев. Дослідження проводили у лютому та червні 2019 p.

Інформація про авторів:

Кратюк Олександр Леонідович, канд. біол. наук, доцент, завідувач кафедри експлуатації лісових ресурсів.

Email: deneshi_ks@ukr.net; https://orcid.org/0000-0002-2661-8074

Цитування за Дсту: Кратюк О. Л. Особливості впливу напіввільного утримання мисливських тварин на діелектричні показники сосни звичайної. Науковий вісник НЛтУ України. 2019, т. 29, № 8. С. 43-45.

Citation APA: Kratiuk, O. L. (2019). Some peculiarities of the influence of semi-free maintenance of game animals on the dielectric parameters of scotch pine. Scientific Bulletin of UNFU, 29(8), 43-45. https://doi.org/10.36930/40290805 
Табл. 1. Лісівничо-таксаційні показники деревостанів на пробних площах

\begin{tabular}{|c|c|c|c|c|c|c|c|}
\hline \begin{tabular}{|c|}
$№$ \\
ח/ח
\end{tabular} & $\begin{array}{c}\text { Квартал } \\
\text { (виділ) }\end{array}$ & $\begin{array}{c}\text { Склад дере- } \\
\text { востану }\end{array}$ & $\begin{array}{l}\text { Тип } \\
\text { лісу }\end{array}$ & $\begin{array}{l}\text { Вік, } \\
\text { років }\end{array}$ & $\begin{array}{l}\text { Пов- } \\
\text { нота }\end{array}$ & $\begin{array}{c}\text { Боні- } \\
\text { тет }\end{array}$ & $\begin{array}{c}\text { Запас, } \\
\text { м }^{3} / \text { га }\end{array}$ \\
\hline 1 & & & & & & I & 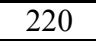 \\
\hline $1 \kappa$ & 18( & & $-\mathrm{C}$ & 45 & 0,80 & II & 30 \\
\hline 2 & & 1 & $\mathrm{C}$ & 57 & 0,75 & $\mathrm{I}^{\mathrm{a}}$ & 300 \\
\hline $2 \kappa$ & & & & 55 & 0,8 & $\mathrm{I}^{\mathrm{a}}$ & 370 \\
\hline 3 & $26(6)$ & तח & - -дC & 66 & 0,85 & $\mathrm{I}$ & 410 \\
\hline $3 \kappa$ & $1 \varepsilon$ & $1+$ Д3 & $\mathrm{B}_{2}-\mathrm{-C}$ & 60 & 0,85 & $\pi$ & 330 \\
\hline 4 & $19(3$ & 8Сз2Бп & $\mathrm{B}_{2}-\mathrm{-LC}$ & 91 & 0,92 & 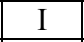 & 340 \\
\hline $4 \kappa$ & $26(4)$ & 7Сз2Бп1Дз & $\mathrm{B}_{2}-\mathrm{-C}$ & 86 & 0,75 & I & 360 \\
\hline
\end{tabular}

Для визначення інтенсивності процесів життєдіяльності сосни звичайної використали діелектричні показники (імпеданс $(R)$ і поляризаційну ємність $(C))$ прикамбіальних тканин лубу на висоті стовбура 1,3 м. Вимірювання виконували аналоговим приладом Ф4320 на частоті 1 кГц за методикою Г. Т. Криницького (Krynytskyj, 1992).

Результати дослідження та їх обговорення. Вольєр на території Явненського лісництва створено згідно $з$ рішенням технічної ради Баранівського лісгос- пзагу від 16.03.1985 р. на площі 56,2 га для розведення оленя плямистого (Cervus nippon Temminck, 1838). Наразі тут постійно утримують до 50 особин основного поголів'я. У межах вольєра виділено 6 типів лісу $\left(\mathrm{A}_{2}-\mathrm{C}\right.$, $\mathrm{B}_{2}-д \mathrm{C}, \mathrm{B}_{3}-д \mathrm{C}, \mathrm{C}_{3}-$ гдС, $\mathrm{C}_{4}-$-гд, $\mathrm{C}_{4}-$ Влч). Домінуючим $\epsilon$ свіжий дубово-сосновий субір, а його площа становить 35,1 га, або 62,5 \% площі вольєра (Kratiuk, 2019).

Наші дослідження електрофізіологічних процесів у сосни звичайної вказують, що незалежно від умов зростання та впливу напіввільного утримання мисливських тварин, діелектричні показники мають чітко виражену динаміку та характеризують сезонні зміни інтенсивності процесів життєдіяльності. Загальну тенденцію простежуємо у поступовому зниженні величини імпедансу i зростанні поляризаційної ємності під час переходу дерев від стану спокою до вегетації. Так, зокрема величина поляризаційної ємності у лютому на ПП №1ПП №4 коливалася у межах $4,32^{ \pm 0,24}-5,68^{ \pm 0,17} \mathrm{nF}$, а у червні зросла до $10,08^{ \pm 0,41}-12,15^{ \pm 0,68} \mathrm{nF}$, натомість імпеданс знизився від $33,93^{ \pm 1,65}-44,40^{ \pm 3,79}$ кОм до $17,85^{ \pm 1,16}$ $21,83^{ \pm 1,35}$ кОм (табл. 2).

Табл. 2. Діелектричні показники сосни звичайної в умовах напіввільного утримання мисливських тварин

\begin{tabular}{|c|c|c|c|c|c|c|c|c|c|}
\hline \multirow{3}{*}{ № ППП } & \multirow{3}{*}{$\begin{array}{c}\text { Квартал (ви- } \\
\text { діл) }\end{array}$} & \multicolumn{2}{|c|}{$C, \mathrm{nF}$} & \multicolumn{2}{|c|}{$R$, кОм } & \multicolumn{2}{|c|}{$C, \mathrm{nF}$} & \multicolumn{2}{|c|}{$R$, кОм } \\
\hline & & $M^{ \pm m}$ & $V, \%$ & $M^{ \pm m}$ & $V, \%$ & $M^{ \pm m}$ & $V, \%$ & $M^{ \pm m}$ & $V, \%$ \\
\hline & & \multicolumn{4}{|c|}{ Лютий 2019 р. } & \multicolumn{4}{|c|}{ Червень 2019 p. } \\
\hline 1 & $26(7)$ & $5,57^{ \pm 0,17}$ & 13,3 & $33,93^{ \pm 1,65}$ & 21,8 & $10,73^{ \pm 0,46}$ & 19,0 & $19,23^{ \pm 1,49}$ & 34,6 \\
\hline $1 \kappa$ & $18(21)$ & $6,76^{ \pm 0,24}$ & 16,2 & $28,55^{ \pm 1,55}$ & 24,2 & $14,88^{ \pm 0,87}$ & 26,3 & $13,35^{ \pm 0,74}$ & 24,8 \\
\hline 2 & $26(8)$ & $5,30^{ \pm 0,16}$ & 14,0 & $35,65^{ \pm 1,34}$ & 16,8 & $11,75^{ \pm 0,59}$ & 22,6 & $17,85^{ \pm 1,16}$ & 29,2 \\
\hline $2 \kappa$ & $26(1)$ & $6,93^{ \pm 0,26}$ & 16,0 & $27,13^{ \pm 1,78}$ & 29,6 & $15,68^{ \pm 0,88}$ & 25,1 & $14,43^{ \pm 0,48}$ & 14,8 \\
\hline 3 & $26(6)$ & $4,32^{ \pm 0,24}$ & 25,4 & $44,40^{ \pm 3,79}$ & 38,2 & $10,08^{ \pm 0,41}$ & 18,6 & $20,68^{ \pm 1,41}$ & 30,6 \\
\hline $3 \kappa$ & $18(23)$ & $7,63^{ \pm 0,25}$ & 14,7 & $27,30^{ \pm 1,29}$ & 21,1 & $16,10^{ \pm 0,95}$ & 26,3 & $13,75^{ \pm 0,81}$ & 26,5 \\
\hline 4 & $19(34)$ & $5,68^{ \pm 0,17}$ & 13,2 & $36,10^{ \pm 2,48}$ & 30,8 & $12,15^{ \pm 0,68}$ & 25,2 & $21,83^{ \pm 1,35}$ & 27,8 \\
\hline $4 \kappa$ & $26(4)$ & $6,53^{ \pm 0,25}$ & 17,2 & $29,55^{ \pm 1,54}$ & 23,4 & $15,25^{ \pm 0,91}$ & 26,7 & $16,15^{ \pm 1,27}$ & 35,2 \\
\hline
\end{tabular}

Як ми вже зазначали, поляризаційна ємність у лютому на дослідних ПП №1-ПП №4 коливалася у межах $4,32^{ \pm 0,24}-5,68^{ \pm 0,17} \mathrm{nF}$, водночас, на контрольних ПП №1кПП №4к вона була вища на 14,9-76,6 \% $\left(t_{\phi}=2,81-9,43\right.$; $\left.t_{05}=2,02\right)$ і становила $6,53^{ \pm 0,25}-7,63^{ \pm 0,25} \mathrm{nF}$ (табл. 3). Коефіцієнт варіації показника як на дослідних так і на контрольних ПП незначний (13,2-16,2 \%), за винятком ПП №3, де він становить 25,4 \%. У цей період саме на ПП №3 показник поляризаційної ємності найнижчий $\left(4,32^{ \pm 0,24} \mathrm{nF}\right)$, натомість на контрольній ПП №3к він найвищий $\left(7,63^{ \pm 0,25} \mathrm{nF}\right)$. Загалом ПП №3 займає чільне місце у наших дослідженнях, оскільки розташована в межах єдиного у вольєрі підгодівельного майданчика. На цій ділянці спостерігаємо найвищу зосередженість тварин у вольєрі. Імпеданс у лютому на дослідних ПП №1-ПП №4 коливався у межах 33,93 $44,40^{ \pm 3,79}$ кОм. На контрольних ПП №1к-ПП №4к він був нищий на $15,9-38,5 \%\left(t_{\phi}=2,24-4,26 ; t_{05}=2,02\right)$ i становив $27,30^{ \pm 1,29}-29,55^{ \pm 1,54}$ КОм. Коефіцієнт варіації на дослідних ПП становить 16,8-38,2\%, а на контрольних - 21,1-29,6 \%. На ПП №3 показник імпеданса найвищий $44,40^{ \pm 3,79}$ кОм. Враховуючи діелектричні показники, можна зробити висновок, що саме на ПП №3 у лютому інтенсивність проходження процесів життєдіяльності у сосни звичайної була найнижчою, що зумовлено активним використанням цієї ділянки мисливськими тваринами.

3 переходом дерев від стану спокою до вегетації поступово простежуємо тенденцію зростання поляризаційної ємності та зниження імпедансу. Так, у червні, за величиною поляризаційної ємності, дослідні насадження сосни звичайної істотно, на $25,5-59,7 \%\left(t_{\phi}=2,73-\right.$ 5,$\left.80 ; t_{05}=2,02\right)$, перевищують контрольні. Поляризаційна ємність на дослідних ПП №1-ПП №4 коливалася у межах $10,08^{ \pm 0,41}-12,15^{ \pm 0,68} \mathrm{nF}$, а на контрольних ПП №1к-ПП №4к вона становила $14,88^{ \pm 0,87}-16,10^{ \pm 0,95} \mathrm{nF}$. Коефіцієнт варіації показника дещо зріс як на дослідних, так і на контрольних ПП і становить 18,6-26,7 \%.

Табл. 3. Достовірність різниці ( $t$-критерій Стьюдента) між величинами діелектричних показників сосни звичайної у деревостанах на території вольєра та поза його межами (контроль)

\begin{tabular}{|c|c|c|c|c|}
\hline \multirow{2}{*}{$№ П П$} & Поляризаційна ємність, $(C)$ & \multicolumn{2}{c|}{ Імпеданс, $(R)$} \\
\cline { 2 - 5 } & $t_{\phi}$ & $\%$ & $t_{\phi}$ & $\%$ \\
\hline \multicolumn{5}{|c|}{ Лютий 2019 p. } \\
\hline 1 & 4,00 & 121,4 & 2,37 & 84,1 \\
\hline 2 & 5,47 & 130,8 & 3,80 & 76,1 \\
\hline 3 & 9,43 & 176,6 & 4,26 & 61,5 \\
\hline 4 & 2,81 & 114,9 & 2,24 & 81,9 \\
\hline \multicolumn{5}{|c|}{ Червень 2019 p. } \\
\hline 1 & 4,21 & 138,7 & 3,54 & 69,4 \\
\hline 2 & 3,69 & 133,4 & 2,72 & 80,8 \\
\hline 3 & 5,80 & 159,7 & 4,25 & 66,5 \\
\hline 4 & 2,73 & 125,5 & 3,05 & 73,9 \\
\hline
\end{tabular}

Примітка: табличне значення $t$-критерію Стьюдента $\left(t_{05}\right)$ становить 2,02 .

Як і в попередній період, на ПП №3 показник поляризаційної ємності найнижчий $\left(10,08^{ \pm 0,41} \mathrm{nF}\right)$, натомість на контрольній ПП №3к він найвищий $\left(16,10^{ \pm 0,95} \mathrm{nF}\right)$. Значення імпеданса у червні на дослідних ПП №1- 
ПП №4 коливалося у межах $17,85^{ \pm 1,16}-21,83^{ \pm 1,35}$ кОм. На контрольних ПП №1к-ПП №4к він був нижчий на 19,2$33,5 \%\left(t_{\phi}=2,72-4,25 ; t_{05}=2,02\right)$ і становив $13,35^{ \pm 0,74}$ $16,15^{ \pm 1,27}$ кОм. Коефіцієнт варіації на дослідних ПП становить 27,8-34,6 \%, а на контрольних - 14,8-35,2 \%.

Висновки. Отже, різниця діелектричних показників дослідних і контрольних насаджень сосни звичайної підтверджує висновок про негативний вплив напіввільного утримання мисливських тварин на життєдіяльність дерев.

Отримані нами експериментальні дані вказують, що вольєрне утримання мисливських тварин у соснових деревостанах уповільнює проходження процесів життєдіяльності у сосни звичайної. На всіх дослідних ділянках величина поляризаційної ємності менша, ніж на контрольних, а показники імпедансу - вищі. Ця закономірність характерна як для вимірів, виконаних у стані відносного спокою (лютий), так і в період вегетації (червень).

Необхідно також відзначити високу індивідуальну мінливість окремих модельних дерев за величиною діелектричних показників, хоча загалом варіювання поляризаційної ємності та імпедансу є середнім.

Отже, діелектричні показники можуть стати надійними маркерами санітарного стану лісових насаджень, а складання відповідних таблиць спростить їх застосування на практиці.

\section{Перелік використаних джерел}

Derekh, O. I. (2014). Dielectric parameters of Oak and Beech trees of areas with different stages of recreational digression in green space of Lviv. Scientific Bulletin of UNFU, 24(8), 119-124.

Derevjanchuk, Yu. L., \& Zaika, V. K. (2011). The morphophysiological reaction of pine trees infecting by Armillariella mellea. Scientific Bulletin of UNFU, 21(9), 18-24. [In Ukrainian].

Karpyn, N. I, \& Zayika, V. K. (2017). Dielectric indexes of Tilia cordata Mill. and Tilia platyphyllos Scop. in various conditions of Lviv City. Scientific Bulletin of UNFU, 27(1), 33-37. https://doi.org/10.15421/40270107
Kerimov, E. I., \& Zaika, V. K. (2018). Dielectric properties of tree species in stands containing european larch. Scientific Bulletin of UNFU, 28(8), 23-27. https://doi.org/10.15421/40280804

Kratiuk, O. L. (2019). Typological structure of forest plantations and biotopic characteristics of enclosures in Central Polissya. Scientific Bulletin of UNFU, 29(2), 62-64. https://doi.org/10.15421/40290212

Krynytskyi, H. T. (1992). Pro metodyku vykorystannia elektrofiziolohichnykh pokaznykiv dlia vyznachennia zhyttiezdatnosti derevnykh roslyn. Forestry, Forest, Paper and Woodworking Industry, 23, 310. [In Ukrainian].

Krynytskyi, H. T., \& Halushka, V. P. (2005). Electro-physiology reaction of Scots pine-tree on taping of resin. Scientific Bulletin of UNFU, 15(2), 8-13. [In Ukrainian].

Krynytskyi, H. T., \& Skolskyi I. M. (2015). Use of dielectric parameters for determination of wych-elm (mountain) trees vitality. Proceedings of the Forestry Academy of Sciences of Ukraine, 13, 83-88. [In Ukrainian].

Krynytskyi, H. T., \& Zaika, V. K. (2004). Elektrofiziolohichna reaktsiia kultur sosny zvychainoi na vysoki rivni khronichnoho radiatsiinoho oprominennia. Status and trends of development of forestry education, science and forestry in Ukraine, 14(5), 8-14. [In Ukrainian].

Krynytskyi, H. T. (1990). Bioelektricheskii metod opredeleniia zhiznesposobnosti drevesnykh rastenii na nachalnykh etapakh ontogeneza. Scientific and Production Association of Space Research, 85, 61. [In Russian].

Krynytskyi, H. T. (2001). Elektrofiziolohichni doslidzhennia derevnykh roslyn v Ukraini. Fiziolohiia roslyn $v$ Ukraini na mezhi tysiacholit. 2, 223-237. [In Ukrainian].

Lavnyy, V. V., \& Krynytskyi, H. T. (2011). Electrophysiological indices of undergrowth trees. Scientific Bulletin of UNFU, 21(17), 8690. [In Ukrainian].

Rybak, Yu. L. (2012). The electrophysiological indices of Scots pine infected by the Melampsora pinitorqua in Western Polesie. Scientific Bulletin of UNFU, 22(12), 42-48. [In Ukrainian].

Rybak, Yu. L., \& Zaika, V. K. (2013). Changes in the electrophysiological activity of Scots pine trees infected by the Lophodermium pinastri. Scientific Bulletin of UNFU, 23(2), 90-96. [In Ukrainian].

Zaika, V. K. (2004). Dielectric parameters of a Pinus sylvestris L. on polluted with radiation territories. Scientific Bulletin of UNFU. 14(1), 12-15. [In Ukrainian].

O. L. Kratiuk

Zhytomyr National Agroecological University, Zhytomyr, Ukraine

\section{SOME PECULIARITIES OF THE INFLUENCE OF SEMI-FREE MAINTENANCE OF GAME ANIMALS ON THE DIELECTRIC PARAMETERS OF SCOTCH PINE}

The use of electrophysiological parameters such as (impedance $(\mathrm{R})$ and polarization capacity $(\mathrm{C})$ ) is a promising method of indicating the stages of the effect of game animals on forest plantations, especially in enclosures. The study was conducted on the territory of the enclosure of Baranivske Hunting Forestry State Enterprise in February and June, 2019. Eight experimental plots were laid, where 4 of them were control ones. In February, capacity polarization on experimental plots ranged from $4.32^{ \pm 0.24}$ to $5.68^{ \pm 0.17} \mathrm{nF}, \mathrm{At}$ the same time on the control plots it was higher than $14.9-76.6 \%\left(t_{\phi}=2.81-9.43 ; t_{05}=2.02\right)$ and it was $6.53^{ \pm 0.25}-7.63^{ \pm 0.25} \mathrm{nF}$. The coefficient of variation of the indicator on both experimental and control plots is negligible (13.2-16.2\%). In February the impedance varied from $33.93^{ \pm 1.65}$ to $44.40^{ \pm 3.79} \mathrm{\kappa Ом}$. On the control plots it was lower $15.9-38.5 \%\left(t_{\phi}=2.24-4.26 ; t_{05}=2.02\right)$ and constituted $27.30^{ \pm 1.29}-29.55^{ \pm 1.54}$ кОм. Variation coefficient equals $16.8-38.2 \%$, on control plots it is $21.1-29.6 \%$. With the transition of trees from dormancy to growing season, the tendency for polarization capacity increasing and impedance decreasing is gradually observed. Therefore, experimental plantations of Silver pine are significantly larger $\left(25.5-59.7 \%\left(t_{\phi}=2.73-5.80 ; t_{05}=2.02\right)\right.$ than control plots by the polarization capacity value in June. Polarization capacity on experimental plots ranged from $10.08^{ \pm 0.41}$ to $12.15^{ \pm 0.68} \mathrm{nF}$, and on the control plots it was $14.88^{ \pm 0.87}-16.10^{ \pm 0.95} \mathrm{nF}$. The coefficient of variation of the indicator slightly increased on both experimental and control plots and equals 18.6-26.7\%. The impedance values on the experimental plots in June were in the range of $17.85^{ \pm 1.16-} 21.83^{ \pm 1.35}$ КОм. It was lower on ЕР№1 c - EP№4 c $\left(19.2-33.5 \%\left(t_{\phi}=2.72-4.25 ; t_{05}=2.02\right)\right.$ and was equal $13.35^{ \pm 0.74}-$ $16.15^{ \pm 1.27}$ кОм. The coefficient of variation on experimental plots is $27.8-34.6 \%$, and on control plots - 14.8-35.2 \%. Experimental data shows that enclosure maintenance of game animals in pine stands slows down life processes of pine trees. The polarization capacity value on all experimental plots is lower than on control plots, and the impedance values are found to be higher. This pattern is characteristic of both measurements performed in the state of relative dormancy (February) and during the growing season (June). To summarize, we should note that dielectric indicators can become reliable markers of the sanitary status of forest plantations, and the preparation of appropriate tables will simplify their application in practice.

Keywords: polarization capacity; impedance; Pinus sylvestris L.; enclosure. 